\title{
ADULTS WITH LOEYS-DIETZ SYNDROME AND VASCULAR EHLERS-DANLOS SYNDROME: A CROSS-SECTIONAL STUDY OF LIFE SATISFACTION
}

Heidi JOHANSEN, MSc ${ }^{1}$, Gry VELVIN, PhD ${ }^{1}$, Kerstin FUGL-MEYER, PhD ${ }^{1,2}$ and Ingeborg Beate LIDAL, PhD ${ }^{1,3}$

From the ${ }^{1}$ National Resource Centre for Rare Disorders, Sunnaas Rehabilitation Hospital, Nesodden, Norway, ${ }^{2}$ Department of Neurobiology, Care Sciences and Society, Division of Family Medicine and Primary Care, Karolinska Institutet, Stockholm, Sweden and ${ }^{3}$ Faculty of Health, Oslo Metropolitan University (OsloMet), Oslo, Norway

Objective: To explore life satisfaction among adults with Loeys-Dietz and those with vascular EhlersDanlos syndrome.

Design: Postal survey in 2018.

Participants and methods: Persons with molecularly verified Loeys-Dietz syndrome or vascular EhlersDanlos syndrome were recruited through the National Resource Centre for Rare Disorders in Norway. The study used the Life Satisfaction Questionnaire 11, Hospital Anxiety and Depression Scale, Fatigue Severity Scale, and questions about physical activity and disease burden. Descriptive statistics were conducted with Bonferroni corrections.

Results: The response rate was $74 \%, 52$ participants, age range $18-68$ years, and $58 \%$ were women. Only half of the participants were satisfied with their lives as a whole. Participants reported dissatisfaction with vocation, somatic health, and sexual life in particular. Participants with vascular Ehlers-Danlos syndrome $(n=18)$ were satisfied with more areas of life than those with Loeys-Dietz syndrome $(n=34)$. Low overall satisfaction was significantly associated with severe fatigue $(p=0.002)$ and symptoms of anxiety $(p=0.001)$.

Conclusion: This study provides important information about living with Loeys-Dietz syndrome and vascular Ehlers-Danlos syndrome. Future studies should identify factors that reduce/increase life satisfaction. Professionals in welfare systems need more information about the unique challenges of living with these diagnoses. Guidelines for research and clinical measurements of life satisfaction should be updated.

Key words: life satisfaction; Loeys-Dietz syndrome; postal questionnaire; vascular Ehlers-Danlos syndrome.

Accepted Oct 8 2021; Epub ahead of print Oct 27, 2021

J Rehabil Med 2021; 53: jrm00239

Correspondence address: Heidi Johansen, TRS National Resource Centre for Rare Disorders, Sunnaas Rehabilitation Hospital, 1450 Nesodden, Norway. E-mail: Heidi.Johansen@sunnaas.no

L oeys-Dietz syndrome (LDS) and vascular EhlersDanlos syndrome (vEDS) are potentially lifethreatening diseases under the umbrella term of rare hereditary thoracic aortic diseases (HTAD). HTADs are known to have serious impacts on the cardiovascular system. With regard to LDS, this concerns the risks of

\section{LAY ABSTRACT}

The aim of this study was to explore life satisfaction in adults with Loeys-Dietz syndrome and those with vascular Ehlers-Danlos syndrome. In 2018, the Life Satisfaction Questionnaire 11 and questionnaires including psychological distress, fatigue, physical activity, and disease burden were sent to adults who were registered at the National Resource Centre for Rare Disorders in Norway. The response rate was $74 \%$, and 52 people aged $18-68$ years participated. Participants who had vascular Ehlers-Danlos syndrome were more often satisfied in most areas of their lives than those with Loeys-Dietz syndrome. Both groups indicated the greatest satisfaction in relation to family life, relationships with their partners, and activities of daily living, while satisfaction with vocations, somatic health, and sexual lives were less common. Low overall life satisfaction was associated with higher levels of fatigue and greater symptoms of anxiety. Future studies should be conducted to gain greater knowledge about factors that reduce and increase their life satisfaction.

aneurysm and dissection of the aorta and other large arteries (1). With vEDS, a fragile connective tissue is associated with a risk of rupturing internal organs in addition to the risks of aneurysm and dissection of large arteries (2). Other structures that are affected may include those in the musculoskeletal system, craniofacial structures, ocular system, and cutaneous features (3).

Most individuals with HTADs live with family members who have the same conditions, and many have close relatives who have died at early ages (4). Persons with HTADs are advised to have regular cardiovascular monitoring, to control their blood pressure with medication, and to schedule prophylactic surgery (1, $2,5)$. As part of the diagnostic process, these patients also receive specific information regarding healthy lifestyles. This includes recommendations for restrictions in their physical activities (6-8) and sometimes also with respect to their jobs, sometimes resulting in early disability retirement (4).

A systematic review published in 2019, concerning quality of life (QoL) of those with HTAD (9), found 20 studies of people with Marfan syndrome (MFS), but no studies of those with LDS or vEDS. Most studies indicate that having a HTAD diagnosis as MFS may 
negatively impact on QoL. In particular, effective coping styles, acceptance of the diseases, and participation in work had positive impacts on QoL (9). In contrast, low educational levels, low incomes, worrying about their personal health, sexual dysfunction, and severe fatigue appeared to have negative impacts on QoL among those with Marfan syndrome. Only a small number of studies found associations between QoL levels and biomedical symptoms, such as aorta dissection and/or aortic surgery (9). Thijssen and colleagues (2020) recently published 2 studies on health-related QoL in adults with HTADs (mostly with MFS) $(10,11)$. They found reduced QoL compared with the general population, especially in younger women (10). In contrast, those with more knowledge about their illnesses, more adequate coping strategies, and better family communication seemed to have fewer symptoms of psychological distress and higher health-related QoL $(10,11)$. They also found reduced health-related QoL among partners of participants with HTAD (11).

There are numerous distinct scales for measuring QoL, life satisfaction, and well-being, both generic and disease specific, and there are also many discrepancies between these methods. However, to the best of our knowledge, no disease-specific scale has been developed to measure any of these constructs with regard to HTADs. The construct of life satisfaction has been seen as a social indicator of meaningfulness and happiness in life (12). The Life Satisfaction Questionnaire 11 (LiSat-11) is among the tools that are considered for assessing patients' levels of satisfaction with their life domains and identifying areas of concern (12). Living with potentially life-threatening conditions, such as LDS and vEDS, may affect several domains of people's lives and perhaps influence their diagnoses in different ways. Therefore, studying domain-specific life satisfaction and the factors that could be associated with this may add important information that could impact the management of, and rehabilitation programmes for, these groups of patients.

The aim of the current study was to explore selfreports of overall and domain-specific life satisfaction in adults with verified LDS or vEDS. Furthermore, this study aimed to compare the life satisfaction findings of those with LDS with those with vEDS, and to investigate the extent to which demographic and clinical factors are associated with different domains for life satisfaction.

\section{METHODS}

\section{Participants and recruitment}

This cross-sectional postal questionnaire survey was part of a larger study of physical functions and psychosocial aspects in adults with HTADs $(4,8,13)$. In January 2018, all patients $(n=70)$, aged 18 years and older, who had molecularly verified LDS or vEDS and were registered at the TRS National Resource Centre for Rare Disorders (14) in Norway were invited to participate in the study. Each eligible individual received a letter by post with information about the study, a consent form to sign, a questionnaire, and a prepaid return-addressed envelope. The non-responders received written reminders 3 weeks later.

\section{Questionnaire}

A study-specific questionnaire for self-reporting was developed in cooperation with representatives from the Norwegian Marfan and Loeys-Dietz Association and the Norwegian Ehlers-Danlos Association.

Sociodemographic variables included the following: sex, age, place of residence (region: south-east, western, middle or northern parts of Norway); family member(s) with LDS or vEDS (yes/no); educational level ( $\leq 13$ or $>13$ years); currently working (yes/no); and current level of disability pension (questions from "National Labour Force Survey" in Norway) (15).

Questions concerning physical activity (PA) were derived from the Nord-Trøndelag Health Study (HUNT) (16). These questions were about the frequency of PA (never, less often than once a week, once a week, 2-3 times a week, or nearly every day), the duration of each PA session (less than 15 min, 15-29 min, $30 \mathrm{~min}-1 \mathrm{~h}$, or more than $1 \mathrm{~h}$ ), and overall intensity of PA (light, moderate, or high) (17). PA levels were established as follows: for each patient, a summary score of PA frequency (coded 1-5), PA duration (coded 1-4), and PA intensity (coded 1-3), was calculated according to the method outlined by Nilsen et al. (18). This score summarized each participant's responses, to give equal weight to each measure according to the following equation: $1 / 5 \times$ frequency $+1 / 4 \times$ duration $+1 / 3 \times$ intensity. This approach gave a maximum score of 1.0 for each of the 3 components of the summary score and a PA summary score range from 0.0 to 3.0 (18). For clinical interpretation, a score of $\geq 2.0$ (i.e. the median score of the study group) or above was classified as a high PA level (13).

Clinical factors included histories of aneurysm/dissection of the aorta and/or of other arteries, of having undergone acute/ prophylactic vascular surgery and/or mitral valve surgery, the use of antihypertensive medication, hernia, organ rupture, pneumothorax, stomach discomfort, impaired vision and/or hearing, neck instability, scoliosis, affected skin or joints, chronic musculoskeletal pain, and asthma/allergy (yes/no). To explore the health burden, 2 sum-scores were calculated on the basis of the number of the following self-reported health problems: cardiovascular burden (0-7) and multi-organ symptom burden (0-12), described in Johansen et al. (4). For clinical interpretation, having the study group's median score or above was regarded as a high level of burden (i.e. $\geq 3.0$ for cardiovascular and $\geq 4.5$ for multi-organ symptoms). One item regarding the history of chronic musculoskeletal pain for a period of more than 3 months in the last year (yes/no) was derived from the Standardised Nordic Questionnaire (19), which has been shown to have acceptable reliability (19).

The LiSat-11, which has 11 items (12), assesses overall satisfaction regarding 1 item (satisfaction with life as a whole) and specific satisfaction regarding 10 items, divided into 4 domains: closeness (family life, partner relationship, and sexual life); health (activity of daily living (ADL), somatic health, and psychological health); leisure (contacts with friends and leisure activities); and provision (vocation and economy). The LiSat-11 has a 6-point scale, ranging from "very dissatisfied" 
(code 1) to "very satisfied" (code 6). For comparison, scores from each item were dichotomized into dissatisfied (scores range $1-4)$ or satisfied (scores range 5-6) in accordance with recommendations (12) and previous studies using LiSat-11 $(20,21)$. LiSat-11 has been found to be valid and reliable $(12,22,23)$.

Symptoms of fatigue were measured using the Fatigue Severity Scale (FSS) (24), a 9-item questionnaire rated on a 7-point response scale. Higher scores indicate higher levels of fatigue. To assess the prevalence of "severe fatigue" vs "non-fatigue", the following cut-off values were used: severe fatigue=FSS mean score $>5$ and non-fatigue $=$ FSS mean score $\leq 5$ (25). The FSS has been found to be valid and reliable $(24,25)$.

The Hospital Anxiety and Depression Scale (HADS) was used to study the prevalence of symptoms of anxiety and depression (26). The HADS consists of 14 items separated into 2 7-item subscales, 1 for anxiety, HADS-A, and 1 for depression, HADSD. Each statement is rated on a 4-point response scale (0-3). A summary score for each subscale of $\geq 8$ points indicates the possible presence of anxiety/depression (26). The Norwegian version of HADS is a well-validated screening instrument for symptoms of psychological distress (27).

To illustrate life satisfaction in the LDS and vEDS groups, we compared our participants with patient populations that experience long-term musculoskeletal pain (28) or cardiac arrest survivors (29) and with reference values from a Swedish general population (12). Populations with long-term musculoskeletal pain or cardiac arrest survivors were regarded as relevant, since people with HTADs are known to have musculoskeletal pain and serious cardiovascular burdens (4).

\section{Data analysis}

Because of the small sample size, descriptive statistics were presented as frequencies and medians with quartiles and ranges, and non-parametric tests were used for comparisons. To explore differences between LDS and vEDS, Fisher's exact test was used for categorical variables and the Mann-Whitney $U$ test for continuous variables.
Bivariate logistic regression analyses were used to explore the associations between the dichotomous dependent LiSat-11 items (life as a whole and 10 life items) and the following independent dichotomous variables (yes/no): sex (women), family member with corresponding diagnosis, full-time work participation, and chronic musculoskeletal pain. The independent continuous variables were age, time since confirmation of diagnosis (years) and PA summary scores, cardiovascular burden, multi-organ burden, total FSS score, HADS-A, and HADS-D. The strength of each association was expressed as an odds ratio (OR) with $95 \%$ confidence interval $(95 \% \mathrm{CI})$ and $p$-value. Multivariate analyses were considered inappropriate because of the small sample size.

In addition, to avoid type 1 errors due to multiple statistical tests, Bonferroni corrections were used in the analyses, as follows: LDS vs vEDS (Table I), 15 variables included $(p<0.003)$ (Table II), 11 variables included $(p<0.005)$ and Lisat-11 domains vs demographic and clinical factors (Table III), with 11 variables included $(p<0.005)$. Bonferroni corrections were also applied when comparing responders with non-responders, with 4 variables included $(p<0.013)$.

There were few missing pieces of data, and the exact numbers for each of the analyses are given in the tables. To assess possible differences between the responders $(n=752)$ and the nonresponders $(n=718), \chi^{2}$ tests were used for categorical variables, and 1-way analysis of variance (ANOVA) analyses for continuous variables. Statistical analyses were conducted using SPSS Statistics for Windows version 25 (IBM corp, Armonk, NY).

\section{Ethics}

The Regional Committees for Medical and Health Research Ethics South East Norway (number 2017/745) approved the study. All participants received written information about the purpose of the study and provided their written informed consent. The results are reported in accordance with the Strengthening the Reporting of Observational Studies in Epidemiology (STROBE) guidelines for observational studies (30).

Table I. Sociodemographic and clinical characteristics in 52 adults with Loeys-Dietz syndrome and vascular Ehlers-Danlos syndrome

\begin{tabular}{|c|c|c|c|}
\hline & $\begin{array}{l}\text { Total study } \\
\text { group, } n=52\end{array}$ & $\begin{array}{l}\text { LDS, } \\
n=34\end{array}$ & $\begin{array}{l}\text { vEDS, } \\
n=18\end{array}$ \\
\hline Median age (quartiles) Age range, years & 43.5 (31.5) $18-68$ & $45.0(21.3) 18-68$ & 38.5 (35.3) 19-68 \\
\hline Sex, women, $n(\%)$ & $30(58)$ & $19(56)$ & $11(61)$ \\
\hline Living with partner, $n(\%)$ & $28(54)$ & $20(59)$ & $8(44)$ \\
\hline Parenthood, $n(\%)$ & $27(52)$ & $21(62)$ & $6(33)$ \\
\hline Family member with corresponding diagnosis, $n(\%)$ & $45(87)$ & $32(94)$ & $13(72)$ \\
\hline Time since diagnosis, median year (quartiles) range years & $6.5(10.0) 1-28$ & $6.0(10.0) 1-28$ & $6.5(6.5) 1-24$ \\
\hline Full-time employed, $n(\%)$ & $14(27)$ & $10(29)$ & $4(22)$ \\
\hline High physical activity level ${ }^{\mathrm{a}}(\geq 2.0), n(\%)$ & $30(58)$ & $18(53)$ & $12(67)$ \\
\hline High cardiovascular burden level ${ }^{\mathrm{b}}$ (median score $\left.\geq 3\right), n(\%)$ & $31(60)$ & $25(74)$ & $6(33)$ \\
\hline High multi-organ burden level ${ }^{\mathrm{C}}$ (median score $\left.\geq 4.5\right), n(\%)$ & $25(48)$ & $19(56)$ & $6(33)$ \\
\hline Chronic musculoskeletal pain, $n(\%)$ & $41(79)$ & $29(85)$ & $12(67)$ \\
\hline Severe fatigue $^{d}($ score $>5), n(\%)$ & $29(56)$ & $21(62)$ & $8(44)$ \\
\hline Indication of moderate/high anxiety level ${ }^{\mathrm{e}}$ (HADS-A score $\left.\geq 8\right), n(\%)$ & $49(94)$ & $33(97)$ & $16(88)$ \\
\hline Indication of moderate/high depression level ${ }^{\mathrm{e}}$ (HADS-D score $\left.\geq 8\right), n(\%)$ & $40(77)$ & $23(68)$ & $17(94)$ \\
\hline
\end{tabular}

*Significance level adjusted with Bonferroni corrections $p<0.003$. ${ }^{a}$ Physical activity level: PA frequency, duration, and intensity; higher score indicates higher PA level. bCardiovascular burden: aorta-aneurism, aorta-dissection, other aneurism, other dissection, aorta-surgery, mitral valve surgery, and use of antihypertensive medication. 'Multi-organ burden: impaired vision/hearing, neck instability, pneumothorax, hernia, organ rupture, scoliosis, skin problems, joint problems, allergies, stomach discomfort, and chronic musculoskeletal pain. ${ }^{d}$ Fatigue severity scale (FSS); higher score indicates more fatigue. ${ }^{e}$ Hospital Anxiety and Depression Scale; the anxiety subscale (HADS-A), and the depression subscale (HADS-D). J Rehabil Med 2021; 53: 202. 
Table II. Satisfaction with life as a whole and 4 domains of life (LiSat-11) in adults with Loeys-Dietz syndrome and vascular EhlersDanlos syndrome

\begin{tabular}{|c|c|c|c|c|c|c|}
\hline \multirow[b]{2}{*}{ Life satisfaction domains and items } & \multicolumn{2}{|c|}{ Total study group, $n=52$} & \multicolumn{2}{|l|}{ LDS, $n=34$} & \multicolumn{2}{|l|}{ vEDS, $n=18$} \\
\hline & $\begin{array}{l}\text { Median score } \\
\text { (quartiles) range }\end{array}$ & $\begin{array}{l}\text { Very satisfied/ } \\
\text { satisfied, } n(\%)\end{array}$ & $\begin{array}{l}\text { Median score } \\
\text { (quartiles) range }\end{array}$ & $\begin{array}{l}\text { Very satisfied/ } \\
\text { satisfied, } n(\%)\end{array}$ & $\begin{array}{l}\text { Median score } \\
\text { (quartiles) range }\end{array}$ & $\begin{array}{l}\text { Very satisfied/ } \\
\text { satisfied, } n(\%)\end{array}$ \\
\hline $\begin{array}{l}\text { Life as a whole } \\
\text { Closeness domain }\end{array}$ & $4.0(1.0) 2-6$ & $25(48)$ & $4.0(2.0) 2-6$ & $17(50)$ & $4.0(1.0) 3-5$ & $8(45)$ \\
\hline Family life $\mathrm{a}^{\mathrm{a}}$ & $5.0(2.0) 2-6$ & $35(69)$ & $5.0(2.0) 3-6$ & $25(69)$ & $5.0(2.0) 2-6$ & $12(66)$ \\
\hline Partner relationship ${ }^{\mathrm{b}}$ & $5.0(3.0) 1-6$ & $27(68)$ & $5.0(3.0) 1-6$ & $18(69)$ & $5.0(3.0) 1-6$ & $9(64)$ \\
\hline Sexual life ${ }^{c}$ & $3.0(3.0) 1-6$ & $18(36)$ & $3.0(3.0) 1-6$ & $9(28)$ & $4.5(2.0) 1-6$ & $9(50)$ \\
\hline Activity of daily living (ADL) & $5.0(2.0) 2-6$ & $36(69)$ & $4.0(1.0) 2-6$ & $20(59)$ & $5.0(0.0) 4-6$ & $16(89)$ \\
\hline Somatic health & $3.0(2.0) 1-6$ & $10(19)$ & $2.0(1.0) 1-5$ & $4(12)$ & $4.0(1.0) 2-6$ & $6(33)$ \\
\hline $\begin{array}{l}\text { Psychological health } \\
\text { Spare-time domain }\end{array}$ & $5.0(2.0) 1-6$ & $29(57)$ & $5.0(2.0) 1-6$ & $18(55)$ & $4.5(1.0) 2-6$ & $11(61)$ \\
\hline Contact with friends & $4.0(2.0) 1-6$ & $23(44)$ & $4.0(2.0) 1-5$ & $13(38)$ & $4.5(2.0) 2-6$ & $10(56)$ \\
\hline $\begin{array}{l}\text { Leisure } \\
\text { Provision domain }\end{array}$ & $4.0(2.0) 1-6$ & $20(38)$ & $3.0(1.0) 1-5$ & $9(27)$ & $5.0(2.0) 2-6$ & $11(61)$ \\
\hline Economy ${ }^{a}$ & $4.0(2.0) 1-6$ & $23(45)$ & $4.0(3.0) 1-6$ & $12(36)$ & $5.0(2.0) 1-5$ & $11(61)$ \\
\hline
\end{tabular}

${ }^{a}$ One LDS participant missing, ${ }^{b} 8$ LDS and 4 vEDS participants missing; ${ }^{c} 2$ LDS participants missing, and ${ }^{d} 5$ LDS participants and 1 vEDS participant missing. Item-response percentages are valid percentages (without counting missing values); significance level adjusted with Bonferroni corrections $p<0.005$.

\section{RESULTS}

\section{Demographic and clinical characteristics}

A total of 52 people answered the questionnaires, yielding a $74 \%$ response rate. There were no statistically significant differences between the responders and non-responders with regard to the following known variables: sex distribution ( $p=0.185)$; age $(p=0.065)$; place of residence (region) ( $p=0.686$ ); or the respective proportions of those who had LDS and vEDS $(p=0.902)(4,13)$.

Table I shows the demographic and clinical characteristics. No statistically significant differences were found between the LDS and vEDS groups. The median age was 43.5 years, women formed a slight majority, and more than half of the participants lived with partners and had children. Approximately $40 \%$ had more than 13 years of education, but only $27 \%$ worked full-time. The median time since the confirmation of their diagnoses was 6.5 years. The majority $(87 \%)$ had family member(s) with corresponding diagnoses. Cardiovascular and multi-organ burden were high, as many as $79 \%$ reported chronic musculoskeletal pain, and 56\% had severe fatigue according to the FSS scores. Many in both groups indicated moderate-to-high levels of symptoms of psychological distress $(94 \%$ had HADS-A scores $\geq 8$ and $77 \%$ had HADS-D scores $\geq 8$ ). A total of $58 \%$ scored high levels with regard to physical activity.

Table III. Associations between demographic and clinical factors and LiSat-11 in 52 adults with Loeys-Dietz syndrome or vascular Ehlers-Danlos syndrome

\begin{tabular}{|c|c|c|c|c|c|c|c|c|c|c|c|}
\hline \multirow[b]{4}{*}{$\begin{array}{l}\text { Demographic and } \\
\text { clinical factors }\end{array}$} & \multicolumn{11}{|c|}{ LiSat 11 domains and items } \\
\hline & \multirow{3}{*}{$\begin{array}{l}\text { Overall } \\
\begin{array}{l}\text { Life as a } \\
\text { whole }\end{array} \\
\text { OR } \\
(95 \% \mathrm{CI})\end{array}$} & \multicolumn{3}{|c|}{ Closeness domain } & \multicolumn{3}{|c|}{ Health domain } & \multicolumn{2}{|c|}{ Leisure domain } & \multicolumn{2}{|c|}{ Provision domain } \\
\hline & & $\begin{array}{l}\text { Family } \\
\text { life }\end{array}$ & $\begin{array}{l}\text { Partner } \\
\text { relationship }\end{array}$ & $\begin{array}{l}\text { Sexual } \\
\text { life }\end{array}$ & $\begin{array}{l}\text { Activity of } \\
\text { daily living }\end{array}$ & $\begin{array}{l}\text { Somatic } \\
\text { heath }\end{array}$ & $\begin{array}{l}\text { Psychological } \\
\text { health }\end{array}$ & $\begin{array}{l}\text { Contacts } \\
\text { with friends }\end{array}$ & Leisure & Economy & Vocation \\
\hline & & $\begin{array}{l}\text { OR } \\
(95 \% \mathrm{CI})\end{array}$ & $\begin{array}{l}\text { OR } \\
(95 \% \mathrm{CI})\end{array}$ & $\begin{array}{l}\text { OR } \\
(95 \% \mathrm{CI})\end{array}$ & $\begin{array}{l}\text { OR } \\
(95 \% \mathrm{CI})\end{array}$ & $\begin{array}{l}\text { OR } \\
(95 \% \mathrm{CI})\end{array}$ & $\begin{array}{l}\text { OR } \\
(95 \% \mathrm{CI})\end{array}$ & $\begin{array}{l}\text { OR } \\
(95 \% \mathrm{CI})\end{array}$ & $\begin{array}{l}\text { OR } \\
(95 \% \mathrm{CI})\end{array}$ & $\begin{array}{l}\text { OR } \\
(95 \% \mathrm{CI})\end{array}$ & $\begin{array}{l}\text { OR } \\
(95 \% \mathrm{CI})\end{array}$ \\
\hline Sex, woman & ns & ns & ns & ns & ns & ns & ns & ns & ns & ns & ns \\
\hline $\begin{array}{l}\text { Chronic } \\
\text { musculoskeletal pain }\end{array}$ & ns & ns & ns & ns & ns & ns & ns & $\begin{array}{l}21.5 \\
(2.5-18.6)\end{array}$ & $\begin{array}{l}31.0 \\
(3.5-27.3)\end{array}$ & ns & ns \\
\hline Fatigue & $\begin{array}{l}0.5 \\
(0.3-0.8)\end{array}$ & ns & ns & ns & $\begin{array}{l}0.2 \\
(0.1-0.6)\end{array}$ & $\begin{array}{l}0.4 \\
(0.3-0.8)\end{array}$ & $\begin{array}{l}0.3 \\
(0.1-0.6)\end{array}$ & $\begin{array}{l}0.5 \\
(0.3-0.8)\end{array}$ & $\begin{array}{l}0.4 \\
(0.2-0.6)\end{array}$ & ns & $\begin{array}{l}0.2 \\
(0.1-0.5)\end{array}$ \\
\hline $\begin{array}{l}\text { Multi-organ burden } \\
(0-12)\end{array}$ & ns & ns & ns & ns & ns & ns & $\begin{array}{l}0.6 \\
(0.4-0.8)\end{array}$ & ns & $\begin{array}{l}0.5 \\
(0.3-0.7)\end{array}$ & ns & ns \\
\hline $\begin{array}{l}\text { Anxiety level } \\
\text { (HADS-A) }\end{array}$ & $\begin{array}{l}1.7 \\
(1.2-2.2)\end{array}$ & ns & ns & ns & ns & ns & $\begin{array}{l}2.5 \\
(1.5-3.9)\end{array}$ & ns & ns & ns & ns \\
\hline
\end{tabular}

OR: odds ratio; 95\% CI: 95\% confidence interval; ns: not significant. Dichotomy variables: Sex, woman: yes $=1$; no $=0$, Family member with corresponding diagnosis: yes $=1$, no $=0$, Working full-time: yes $=1$, no $=0$, and Chronic musculoskeletal pain: yes $=1$, no $=0$. Continuous variables: age; Time since diagnosis (years); Fatigue Severity Scale (FSS); number of cardiovascular burdens (0-7); number of multi-organ burdens (0-12); Physical activity levels, and Anxiety and Depression levels (Hospital Anxiety and Depression Scale: the anxiety subscale and depression subscale). NB: The following variables are not presented in the table because no statistically significant results were found: family member with corresponding diagnosis; time since diagnosis (years); working full-time; physical activity levels; cardiovascular burdens; and depression levels (Hospital Anxiety \& Depression Scale). Significance level adjusted with Bonferroni corrections $p<0.005$. 


\section{Life Satisfaction}

A relatively high proportion of participants were satisfied with their family lives (69\%), their ADL (69\%), and their relationships with their partners (68\%) (Table II). A larger proportion of those with vEDS were more frequently satisfied with regard to most items/domains than of those with LDS; however, no statistically significant differences were found. In both the LDS and the vEDS groups, few were satisfied with their sexual lives $(28 \%$ and $50 \%$, respectively), somatic health ( $12 \%$ and $33 \%$, respectively), and vocations ( $24 \%$ and $29 \%$. respectively).

Table III shows the associations between the dichotomous dependent LiSat-11 items and demographic and clinical factors. Low levels of fatigue and of HADS-A were both positively associated with satisfaction with life as a whole (OR $0.5 ; 95 \%$ CI $0.3-0.8$; $p=0.002$ and OR $1.7 ; 95 \%$ CI $1.2-2.2 ; p=0.001$ ).

Closeness domain. Satisfaction with family lives, relationships with partners, and sexual lives were not significantly associated with any of the demographic or clinical factors examined.

Health domain. Low level of fatigue was associated with being satisfied with ADL (OR 0.2; 95\% CI $0.1-0.6 ; p=0.002$ ), somatic health (OR $0.4 ; 95 \%$ CI $0.3-0.8 ; p=0.003)$, and psychological health (OR 0.3 ; $95 \%$ CI $0.1-0.6 ; p=0.001)$. In addition, low multiorgan burden (OR $0.6 ; 95 \%$ CI $0.4-0.8 ; p=0.002$ ) and low HADS-A score (OR 2.5; 95\% CI 1.5-3.9; $p<0.001$ ) were associated with satisfaction with psychological health.

Leisure domain. Low level of fatigue and no chronic musculoskeletal pain were significantly associated with satisfaction with contact with friends (OR $0.5 ; 95 \%$ CI $0.3-0.8 ; p=0.002$ and OR 21.5; 95\% CI 2.5-18.6; $p=0.005$ ) and leisure (OR 0.4; 95\% CI 0.2-0.6; $p<0.001$ and OR 31.0; 95\% CI 3.5-27.3; $p=0.002)$. In addition, low level of multi-organ burden (OR 0.5; $95 \%$ CI $0.3-0.7 ; p=0.001$ ) was significantly associated with satisfaction with leisure activities.

Provision domain. Low level of fatigue was significantly associated with satisfaction with vocations (OR 0.2 ; 95\% CI $0.1-0.5 ; p=0.001$ ) (Table III).

\section{Life satisfaction and comparison with other study populations}

Fig. 1 shows the proportion of people who were satisfied with life as a whole and the 10 LiSat-11 items among participants with LDS and those with vEDS, as well as the reference values from a Swedish general population (age range 16-74 years) (12), patients expe-

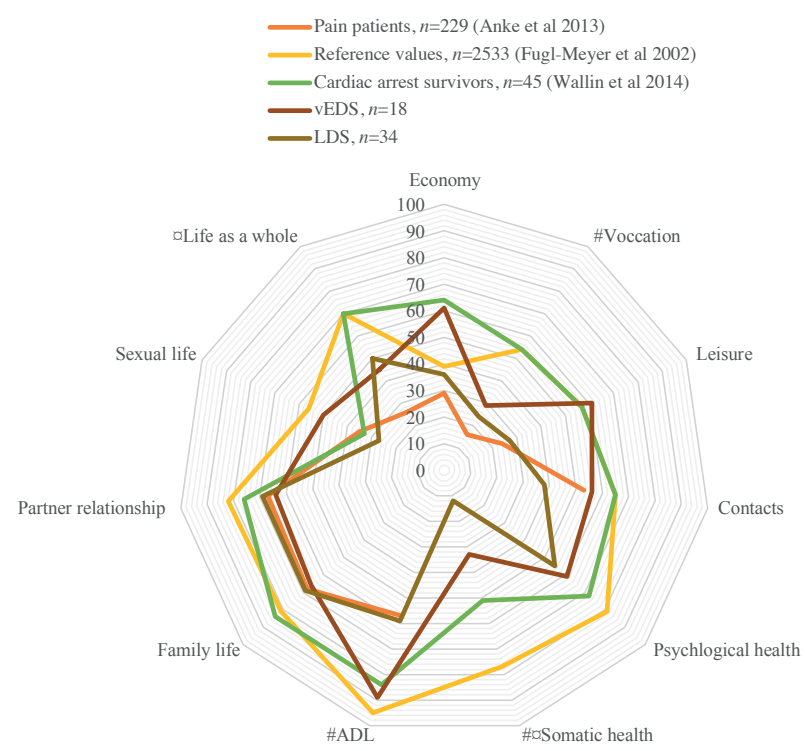

Fig. 1. Satisfaction with life as a whole and 10 life items: proportions of those who reported very satisfied/satisfied among participants with Loeys-Dietz syndrome (LDS) or vascular Ehlers-Danlos syndrome (vEDS), patients with long-term musculoskeletal pain, cardiac arrest survivors, and reference values from the Swedish general population. Because there is no Norwegian norm data on LiSat-11, Swedish reference values were used for comparison (Fugl-Meyer 2002). \#Life domains with the largest differences between LDS and the Swedish reference population. $x$ Life domains with the largest differences between vEDS and the Swedish reference population

riencing long-term musculoskeletal pain (mean age 42 (SD 10) years) (28), and cardiac arrest survivors (mean age 64 (SD 13) years) (29). The differences between the LDS group and the reference values were greatest for ADL ( $59 \%$ vs $95 \%)$, somatic health (12\% vs $77 \%$ ) and vocation ( $24 \%$ vs $54 \%$ ). Those in the LDS group who were satisfied were found to have approximately the same proportions as the patients with long-term musculoskeletal pain (28). The vEDS group differed from the reference values, specifically with regard to life as a whole ( $45 \%$ vs $79 \%)$ and somatic health $(33 \%$ vs $77 \%$ ). The proportions satisfied with the different life domains among those vEDS were almost the same as for the cardiac arrest survivors (29).

\section{DISCUSSION}

To our knowledge, this is the first study to investigate life satisfaction in adults with molecularly confirmed LDS and vEDS. Relatively few participants were satisfied with their sexual lives, somatic health, and vocation domains. However, quite many participants were satisfied with their family lives, relationships with partners, and ADLs. Low levels of fatigue, low multi-organ burdens, and low HADS-A scores were associated with higher scores in several LiSat-11domains. Overall, participants in the vEDS group were satisfied with more items/domains of life than those in the LDS group. 


\section{Life as a whole}

Approximately $50 \%$ of participants were satisfied with life as a whole. This figure was lower than among cardiac arrest survivors (29), which, in turn, was somewhat lower than the reference values (12). In contrast, Stålnacke et al. (24) and Anke et al. (28) found that fewer than $30 \%$ of patients with long-term musculoskeletal pain were satisfied with life as a whole $(24,28)$. We did not find any significant associations between pain and satisfaction with life as a whole or with symptoms of depression. Since we found that low levels of fatigue and low HADS-A scores were associated with being satisfied with life as a whole, we speculate that pain, symptoms of anxiety, and fatigue influence each other and consequently affect overall satisfaction. To gain better information, these aspects could be further explored in studies with larger HTAD populations.

\section{Closeness domain}

Relatively many participants with LDS and vEDS were satisfied with the domains of family life and relationships with partners. Fewer participants were satisfied with their sexual lives, especially among those with LDS. It is notable that participants with LDS had more extended disease burdens than those with vEDS (4). We speculate that a higher level of disease burden could imply a greater fear of dissection and tissue rupture. If so, this may affect satisfaction with sexual life (i.e. fear of the physical strain during sexual activities) and provide an explanation for the differences between the groups. Among cardiac arrest survivors, few reported being satisfied with the domains of sexual life and somatic health, while a majority reported satisfaction in most other life domains 6 months after acute illness. In addition, their overall life satisfaction improved over time (29). In the present study, no associations were found between the times since their diagnoses and any of the LiSat-11 domains. In a recently published follow-up study on adults with Marfan syndrome (31), a reduction in physical function was found after 10 years, while mental functioning was approximately the same. The authors found no association between decline in physical function and having any organ that was affected (31).

\section{Health domain}

Overall, more participants in the vEDS group than in the LDS group were satisfied with the somatic health and ADL domains. This can be understood in light of the fact that the participants with LDS in the current study had higher disease burdens than those with vEDS, and a higher degree of disease burden has been shown to have a negative effect on satisfaction with health domains (32). This also agrees with our findings, which showed that higher levels of disease burden, higher levels of fatigue, and greater symptoms of anxiety were associated with dissatisfaction with regard to some of the health domains.

A higher proportion of participants were dissatisfied with their somatic health, while more were satisfied with their psychological health. We anticipate that the extent of health problems of their diagnoses (4) probably influenced their experiences of satisfaction with somatic health. Surprisingly, psychological health was less affected. Maybe the relatively high satisfaction with their family lives and relationships with their partners have had a positive influence on psychological health.

\section{Leisure domain}

Among participants with LDS, only 27\% were satisfied with leisure and $38 \%$ with their contacts with friends. This was fewer than among the participants with vEDS ( $61 \%$ vs $56 \%$ ), the reference values (12), and the cardiac arrest survivors (29), but similar to the proportion among patients with long-term musculoskeletal pain (28). In addition to an extensive disease burden in the LDS group, they more frequently had children than did participants with vEDS. This makes us speculate that these factors may have affected the LDS participants' possibilities of having their own active leisure and time with friends. This may be among the explanations regarding the different proportions satisfied with leisure between the 2 groups.

\section{Provision domain}

Fugl-Meyer et al. (12) found life satisfaction to be sex independent in the general Swedish population, while higher ages were systematically and positively associated with satisfaction with vocation and economy. In the present study, the sex independence was confirmed, and no age-dependent associations were found.

Very few participants were satisfied with the vocation domain, with few working full-time, and many having stopped working before retirement age (4). High level of fatigue was significantly associated with dissatisfaction with vocation, which is in accordance with findings in other studies of women and men with HTADs $(33,34)$, thus indicating that fatigue may impact the ability to work. Working has been shown to improve social conditions, finances, self-esteem, and independence in HTADs, which, in turn, have positive impacts on quality of life $(10,11)$. Reduced ability to work usually means lower incomes and therefore less satisfaction with economic situations. The severity of HTADs and/or difficulties adjusting to work situations 
may lead to early retirement in some individuals (4). Moreover, healthcare professionals may regard the work situations of those with HTADs as being too strenuous and, indeed, as potential health risks; i.e. affecting blood pressure. Although such factors were not investigated in the current study, they may have contributed to the reports of low work participation and dissatisfaction with vocation.

\section{Strengths and limitations}

This study has several strengths: a high response rate, the inclusion of only people with genetically verified diagnoses, residents from all regions of Norway, and thorough and complete data-collection (i.e. very few missing data).-

Some limitations should, however, be noted: individuals who register in the database at the TRS National Resource Centre for Rare Disorders that was used for recruiting the study participants, usually register because of their need for services, such as diagnostic information, advice on lifestyle behaviour and/or welfare services. Therefore, those who choose to register may differ from those who do not (35). Furthermore, it is possible that some participants were relatives, since we did not collect information on this, and this might cause a confounding factor, because family members may influence each other's perceptions of health and thus their levels of life satisfaction. The relatively small sample size results in low statistical power for several analyses. To avoid type 1 errors, we therefore used Bonferroni corrections with the analyses comparing groups, and this statistical method indicates significance with lower cut-off levels.

\section{Conclusion}

This study adds new and important information about life satisfaction in people with diagnoses of vEDS or LDS. Only half of the participants were satisfied with life as a whole, and they reported dissatisfaction with several domains of life, in particular regarding their satisfaction with sexual life, somatic health, and vocation domains. Severe fatigue was found to be significantly associated with dissatisfaction in several life domains.

Future studies of patients with HTAD should include measurements of satisfaction, to increase knowledge of important life domains and factors that promote life satisfaction. Furthermore, such measures can be used as quality indicators of treatment and follow-up management. In addition, it is also important to disseminate information on the unique challenges of living with HTADs to those working in the welfare system.

\section{ACKNOWLEDGEMENTS}

The authors wish to thank the Norwegian Marfan and LoeysDietz Association, the Norwegian Ehlers-Danlos Association, and all participants who made this study possible. The TRS National Resource Centre for Rare Disorders, Sunnaas Rehabilitation Hospital, in Norway, funded the study.

The data underlying this study is restricted by the Regional Committees for Medical and Health Research Ethics South East Norway. Because of these ethical restrictions regarding the potential for identifying patient information, data is not available.

The authors have no conflicts interests to declare.

\section{REFERENCES}

1. Loeys BL, Dietz HC. Loeys-Dietz syndrome. In: Adam MP, Ardinger $\mathrm{HH}$, Pagon RA, Wallace SE, Bean LJH, Mirzaa G, et al., editors. GeneReviews((R)). Seattle (WA): University of Washington; 1993-2018. [Updated 2018; cited 2020 Jan 10].

2. Byers PH, Belmont J, Black J, De Backer J, Frank M, Jeunemaitre $X$, et al. Diagnosis, natural history, and management in vascular Ehlers-Danlos syndrome. Am J Med Genet C Semin Med Genet 2017; 175: 40-47.

3. Meester JAN, Verstraeten A, Schepers D, Alaerts M, Van Laer L, Loeys BL. Differences in manifestations of Marfan syndrome, Ehlers-Danlos syndrome, and Loeys-Dietz syndrome. Ann Cardiothorac Surg 2017; 6: 582-594.

4. Johansen $\mathrm{H}$, Velvin $\mathrm{G}$, Lidal I. Adults with Loeys-Dietz syndrome and vascular Ehlers-Danlos syndrome: a crosssectional study of health burden perspectives. Am J Med Genet A 2020; 182: 137-145.

5. Milewicz DM, Regalado E. Heritable thoracic aortic disease overview. In: Adam MP, Ardinger $\mathrm{HH}$, Pagon RA, Wallace SE, Bean LJH, Mirzaa G, et al., editors. GeneReviews ( $(R))$. Seattle (WA): University of Washington; 1993-2017. [Updated 2017; cited 2020 Dec 10].

6. Cheng A, Owens D. Marfan syndrome, inherited aortopathies and exercise: what is the right answer? $\mathrm{Br}$ J Sports Med 2016; 50: 100-104.

7. Thijssen CGE, Bons LR, Gokalp AL, Van Kimmenade RRJ Mokhles MM, Pelliccia A, et al. Exercise and sports participation in patients with thoracic aortic disease: a review. Expert Rev Cardiovasc Ther 2019; 17: 251-266.

8. Velvin G, Johansen H, Vardeberg K, Sjogren Fugl-Meyer K, Wilhelmsen JE, Lidal I. Physical exercise for people with hereditable thoracic aortic disease. A study of patient perspectives. Disabil Rehab 2019: 1-8.

9. Velvin G, Wilhelmsen JE, Johansen $H$, Bathen $T$, Geirdal AO. Systematic review of quality of life in persons with hereditary thoracic aortic aneurysm and dissection diagnoses. Clin Genet 2019; 95: 661-676.

10. Thijssen CG, Doze DE, Gökalp AL, Timmermans J, Peters JB, Elbers-van de Ven LH, et al. Male-female differences in quality of life and coping style in patients with Marfan syndrome and hereditary thoracic aortic diseases. J Genet Couns 2020; 00: 1-11.

11. Thijssen CG, Dekker S, Bons LR, Gökalp AL, Kauling RM, van den Bosch $A E$, et al. Health-related quality of life and lived experiences in males and females with thoracic aortic disease and their partners. Open Heart 2020; 7: e001419.

12. Fugl-Meyer AR, Melin R, Fugl-Meyer KS. Life satisfaction in 18-to 64-year-old Swedes: in relation to gender, age, partner and immigrant status. J Rehab Med 2002; 34: 239-246.

13. Johansen H, Velvin G, Lidal I. Adults with Loeys-Dietz syndrome and vascular Ehlers-Danlos syndrome: a cross- 
sectional study of patient experiences with physical activity. Disabil Rehabil 2020: 1-8.

14. TRS National Resource Centre for Rare Disorders, Norway, Norwegian [Internet]. Information [cited 2020 Dec 15]. Available from: https://www.sunnaas.no/fag-og-forskning/ kompetansesentre-og-tjenester/trs-kompetansesenter-forsjeldne-diagnoser (in Norwegian).

15. Køber T, Bø TP. [The Norwegian population's connection to the labour market 2018]. Norwegian, Statistics Norway 2019 [cited 2020 Dec 15]. Available from: https://www.ssb. no/arbeid-og-lonn/artikler-og-publikasjoner/befolkningenstilknytning-til-arbeidsmarkedet-2018. (In Norwegian).

16. HUNT Research Centre [The Nord-Trøndelag Health Study] [Internet]. HUNT3 Fitness Project. Questionnaire - NT3FitnQ20 2019 [cited 2020 Feb 15]. Available from: https:// hunt-db.medisin.ntnu.no/hunt-db/\#/studypart/189.

17. Reed, JL, Pipe AL. Practical approaches to prescribing physical activity and monitoring exercise intensity. Can J Cardiol 2016; 32: 514-522.

18. Nilsen TI, Romundstad PR, Petersen H, Gunnell D, Vatten LJ. Recreational physical activity and cancer risk in subsites of the colon (the Nord-Trondelag Health Study). Cancer Epidemiol Biomarkers Prev 2008; 17: 183-188.

19. Kuorinka I, Jonsson B, Kilbom A, Vinterberg H, BieringSorensen F, Andersson G, et al. Standardised Nordic questionnaires for the analysis of musculoskeletal symptoms. Appl Ergon 1987; 18: 233-237.

20. Stălnacke BM. Life satisfaction in patients with chronic pain-relation to pain intensity, disability, and psychological factors. Neuropsyc Dis Treat 2011; 7: 683-689.

21. Wilhelmson K, Fritzell E, Eklund K, Dahlin-Ivanoff S. Life satisfaction and frailty among older adults. Health Psychol Res 2013; 1: 167-172.

22. Melin R, Fugl-Meyer KS, Fugl-Meyer AR. Life satisfaction in 18- to 64-year-old Swedes: in relation to education, employment situation, health and physical activity. J Rehabil Med 2003; 35: 84-90.

23. Ekstrand $E$, Lexell J, Brogårdh C. Test-retest reliability of the life satisfaction questionnaire (LiSat-11) and association between items in individuals with chronic stroke. J Rehabil Med 2018; 50: 713-718.

24. Krupp LB, LaRocca NG, Muir-Nash J, Steinberg AD. The fatigue severity scale. Application to patients with multiple sclerosis and systemic lupus erythematosus. Arch Neurol 1989; 46: 1121-1123.

25. Lerdal A, Wahl A, Rustoen T, Hanestad BR, Moum T. Fatigue in the general population: a translation and test of the psychometric properties of the Norwegian version of the fatigue severity scale. Scan J Public Health. 2005; 33: $123-130$.

26. Zigmond AS, Snaith RP. The Hospital Anxiety and Depression scale. Acta Psychiatr Scand 1983; 67: 361-370.

27. Mykletun A, Stordal E, Dahl AA. Hospital Anxiety and Depression (HAD) scale: factor structure, item analyses and internal consistency in a large population. Br J Psychiatry 2001; 179: 540-544.

28. Anke $A$, Damsgård $E$, Røe $C$. Life satisfaction in subjects with long-term musculoskeletal pain in relation to pain intensity, pain distribution and coping. J Rehabil Med 2013; 45: 277-285.

29. Wallin E, Larsson M, Rubertsson S, Kristofferzon M-L. Cardiac arrest and hypothermia treatment-function and life satisfaction among survivors in the first 6 months. Resuscitation 2014; 85: 538-543.

30. von Elm E, Altman DG, Egger M, Pocock SJ, Gotzsche PC, Vandenbroucke JP. The Strengthening the Reporting of Observational Studies in Epidemiology (STROBE) statement: guidelines for reporting observational studies. J Clin Epidemiol 2008; 61: 344-349.

31. Vanem TT, Rand-Hendriksen S, Brunborg C, Geiran OR, Røe C. Health-related quality of life in Marfan syndrome: a 10-year follow-up. Health Qual Life Outcomes (2020) 18: 376. Available from: https://doi.org/10.1186/s12955020-01633-4

32. Diener E. Understanding Scores on the Satisfaction with Life Scale 2006 [cited 2020 Dec 15]. Available from: http:// internal.psychology.illinois.edu/ ediener/SWLS.html.

33. Velvin G, Bathen T, Rand-Hendriksen S, Geirdal AO. Work participation in adults with Marfan syndrome: Demographic characteristics, MFS related health symptoms, chronic pain, and fatigue. Am J Med Genet A 2015; 167: 3082-3090.

34. Goldfinger JZ, Preiss LR, Devereux RB, Roman MJ, Hendershot TP, Kroner BL, et al. Marfan syndrome and quality of life in the GenTAC registry. J Am Coll Cardiol 2017; 69: 2821-2830.

35. Lunde ES, Otnes B, Ramm J. [Sosial ulikhet i bruk av helsetjenester. En kartlegging 2017 [Social inequality in the use of health services, a survey 2017]. [cited 2020 Des15]. Avalilable from: https://www.ssb.no/helse/artikler-ogpublikasjoner/sosial-ulikhet-i-bruk-av-helsetjenester (in Norwegian).

36. Jacobsen EL, Bye A, Aass N, Fossa SD, Grotmol KS, Kaasa $S$, et al. Norwegian reference values for the Short-Form Health Survey 36: development over time. Qual Life Res 2018; 27: 1201-1212. 